\title{
Pantoprazole-induced acute kidney injury: A case report
}

\author{
TAO PENG ${ }^{1}$, ZHAO HU $^{1}$, HONGNAN ZHENG $^{2}$, JUNHUI ZHEN $^{3}$, CHENGJUN MA $^{1}$ and XIANGDONG YANG ${ }^{1}$ \\ ${ }^{1}$ Department of Nephrology, Shandong University Qilu Hospital, Jinan, Shandong 250012; ${ }^{2}$ Department of \\ Nephrology, Jinan Third People's Hospital, Jinan, Shandong 250010; ${ }^{3}$ Department of Pathology, \\ Shandong University Qilu Hospital, Jinan, Shandong 250012, P.R. China
}

Received October 20, 2017; Accepted February 16, 2018

DOI: $10.3892 /$ etm.2018.6088

\begin{abstract}
The present study reports a case of pantoprazole-induced acute kidney disease. The patient was diagnosed with acute kidney injury with wide interstitial inflammation and eosinophil infiltration. Following 1 month of glucocorticoid therapy, the patient's serum creatinine and urea nitrogen decreased to within normal ranges. The presentation, clinical course, diagnosis and prognosis of pantoprazole-induced acute kidney injury are discussed herein to highlight the importance of early and correct diagnosis for good prognosis. Disease characteristics include short-term increased serum creatinine levels that respond to glucocorticoid treatment. The patient had no history of chronic kidney disease or proteinuria and presented with increased serum creatinine following treatment with pantoprazole. Following the end of pantoprazole treatment, short-term RRT and long-term prednisolone was administered, then serum creatinine returned to normal. Pantoprazole-induced acute kidney injury is commonly misdiagnosed and late diagnosis results in poor patient prognoses. Misdiagnosis leads to the administration of treatments that may exacerbate the condition, so appropriate diagnosis and treatment for pantoprazole-induced acute kidney injury is necessary.
\end{abstract}

\section{Introduction}

Acute kidney injury comprises of a group of symptoms that include a sudden drop in renal function during a short time ( $<24 \mathrm{~h}$ ) defined as an increase of $\geq 0.5 \mathrm{mg} / \mathrm{dl}$ in serum creatinine (SCr) (1). The occurrence of azotemia, and imbalances of water and/or electrolytes and/or $\mathrm{pH}$ are associated with oliguria $(<400 \mathrm{ml} / 24 \mathrm{~h}$ or $17 \mathrm{ml} / \mathrm{h})$ or aurine $(<100 \mathrm{ml} / 24 \mathrm{~h})(2)$. Acute renal injury can be divided into pre-renal, renal and post-renal, each with separate etiologies and pathogeneses (3).

Correspondence to: Dr Xiangdong Yang, Department of Nephrology, Shandong University Qilu Hospital, 107 Wenhua Xi Road, Jinan, Shandong 250012, P.R. China

E-mail: sesame_oil@126.com

Key words: pantoprazole, acute kidney injury, prognosis, glucocorticoids, misdiagnosis
Drug-induced acute kidney injuries are common in clinical practice, and misdiagnosis and late diagnosis of drug-induced acute kidney injury have occurred (4).

Pantoprazole is used clinically as an irreversible proton pump inhibitor (PPI) to reduce gastric acid secretion (5). Pantoprazole is activated in the acidic environment of gastric parietal cells as cyclic sulphonamides and specifically binds to mercapto groups on the proton pump (i.e., HtK + -ATPase) to inhibit $\mathrm{H}^{+}$secretion (6). A number of side effects of pantoprazole have been reported, with a small number of patients reporting headache, dizziness, nausea, diarrhea, bloating, skin itching and skin rash, as well as reports of elevated aminotransferase, leukopenia and thrombocytopenia (7-9). However, there have been few reports of kidney damage associated with pantoprazole. Early and correct diagnosis of pantoprazole-induced acute kidney injury may be the key to treatment. The right diagnosis and early treatment are closely associated with improved prognosis.

In the present study, a case of acute kidney injury induced by pantoprazole is presented. The patient presented with extensive interstitial inflammation and eosinophil infiltration in the kidney tissue. Following 1 month of glucocorticoid therapy, serum creatinine and urea nitrogen levels returned to normal.

\section{Case report}

A 50-year-old woman with a $>5$ year history of diabetes mellitus presented with pantoprazole-induced acute kidney disease in July 2017 at Shandong University Qilu Hospital (Jinan, China). Blood glucose was usually controlled within the normal range (reference range, 3.6-6.1 mmol/l) and there was no prior medical history of hypertension, hematuria, proteinuria or other kidney disease. According to her own narrative, the patient had a history of chronic gastritis, which was not treated. There was no history of treatment with and pharmacological agents or Chinese herbal medicine with the exception of long-acting insulin by subcutaneous injection once per day. The protocol of the current study was approved by the ethics committee of Shandong University Qilu Hospital. Written informed consent was obtained from the patient after the patient and the patient's family seriously and carefully read and understood a written summary of the study plan.

Prior to admission to the emergency department, the patient had elevated serum glucose $(16.3 \mathrm{mmol} / 1$, measured at a community clinic) for 1 day and complained of mild nausea 
without vomiting, abdominal pain or diarrhea. The results of laboratory tests revealed serum creatinine (Scr) $78 \mu \mathrm{mol} / 1$ (normal reference value, 53-97 $\mu \mathrm{mol} / \mathrm{l}$ ), blood urea nitrogen $3.7 \mathrm{mmol} / 1$ (normal reference value, 2.3-7.8 mmol/l), hemoglobin (Hgb) $136 \mathrm{~g} / 1$ (normal reference value, 115-165 g/l), serum glucose (Glu) $15.7 \mathrm{mmol} / 1$ (normal reference value, 3.1-5.6 mmol/1) and $24 \mathrm{~h}$ urine volume 1,600 $\mathrm{ml}$ (normal reference value, 1,000-2,000 $\mathrm{ml} / 24 \mathrm{~h}$ ). All relative indicators were measured from venous blood drawn $8 \mathrm{~h}$ after fasting and centrifuged at $11,000 \times \mathrm{g}$ for $15 \mathrm{~min}$ at $25^{\circ} \mathrm{C}$. Due to the patient's mild nausea and history of chronic gastritis, the patient was treated with pantoprazole (40 mg once a day, intravenous infusion) and intermediate acting insulin (12 $\mathrm{U}$ at 8 a.m. and $10 \mathrm{U}$ at 5 p.m., subcutaneous injection) for 2 days. Following treatment, Glu recovered to $6.4 \mathrm{mmol} / \mathrm{l}$; however, the patient reported increased nausea, $24 \mathrm{~h}$ urine output was significantly reduced to $300 \mathrm{ml}$ (Fig. 1) and Scr increased from 78 to $750 \mu \mathrm{mol} / \mathrm{l}$ (Fig. 2). Blood urea nitrogen also increased from to $18.9 \mathrm{mmol} / \mathrm{l}$ (Fig. 3). The patient was admitted to the Department of Nephrology.

Upon admission a physical examination revealed mild edema in bilateral eyelids and lower limbs without malar rash, oral ulcers or diffuse alopecia. Pertinent laboratory findings included Scr $781 \mu \mathrm{mol} / 1, \mathrm{Hgb} 101 \mathrm{~g} / 1$, blood urea nitrogen $24.3 \mathrm{mmol} / \mathrm{l}$, Glu $5.7 \mathrm{mmol} / \mathrm{l}$ and $24 \mathrm{~h}$ urine volume $170 \mathrm{ml}$. White blood cell and platelet counts were normal. Parathyroid hormone, $\mathrm{Ca}^{2+}$ and $\mathrm{P}^{3+}$ levels were normal. Tests for anti-glomerular basement membrane antibody and anti-neutrophil antibody were negative. Glycosylated hemoglobin was $6.1 \%$ and the brain natriuretic peptide (BNP) concentration was $1,863 \mathrm{pg} / \mathrm{ml}$. Urinary $\beta_{2}$ microglobulin concentration was $1.2 \mathrm{mg} / \mathrm{l}$ and the urinary albumin-creatinine ratio was $0.01 \mathrm{~g} / \mathrm{gCr}$. Anti-nuclear antibody spectrum, tumor markers, thyroid function, immunoglobulin, complement $\mathrm{C} 3$ and $\mathrm{C} 4$, hepatitis $\mathrm{B}$ virus quantification and coagulation results were all within the normal range. Serum immunofixation electrophoresis was negative. Renal ultrasonography revealed that the kidney volume was above normal (right, 12.1x6.3x4.4 cm; left, $11.7 \times 6.9 \times 4.9 \mathrm{~cm}$; reference range 10-12.1 x5-6x3-4 cm) (10). Lung X-rays revealed no evidence of inflammation.

Following admission to the Department of Nephrology, the patient immediately underwent renal biopsy. A total of two renal biopsy specimens $\sim 1.5 \mathrm{~cm}$ in length were obtained containing $100 \%$ cortex. Specimens were stained with hematoxylin and eosin at $25^{\circ} \mathrm{C}$ for $40 \mathrm{~min}$. Microscopy revealed 17 glomeruli in each section without complete or peribulbar fibrosis (Fig. 4). No proliferation was observed in the mesangial cells and matrix and no glomerular capillary thickening was reported. Masson staining was performed at $25^{\circ} \mathrm{C}$ for $60 \mathrm{~min}$ and no immune complex deposition in the capillary walls was observed (Fig. 5). Periodic acid-silver methenamine staining was performed at $25^{\circ} \mathrm{C}$ for $30 \mathrm{~min}$ and revealed no atrophy in the tubules and only a few tubules were dilated with flat epithelial cells (Fig. 6). Severe edema with multifocal lymphocyte, monocyte and eosinophil infiltration was observed in the renal interstitium; however, there was no thickening of arterial walls (Figs. 4-6). All samples were observed using a light microscope (magnification, $\mathrm{x} 400$ ).

Sections (70-nm-thick) were fixed by $2.5 \%$ glutaraldehyde solution and $1 \%$ osmium tetroxide at $4^{\circ} \mathrm{C}$ for 4 and $2 \mathrm{~h}$,

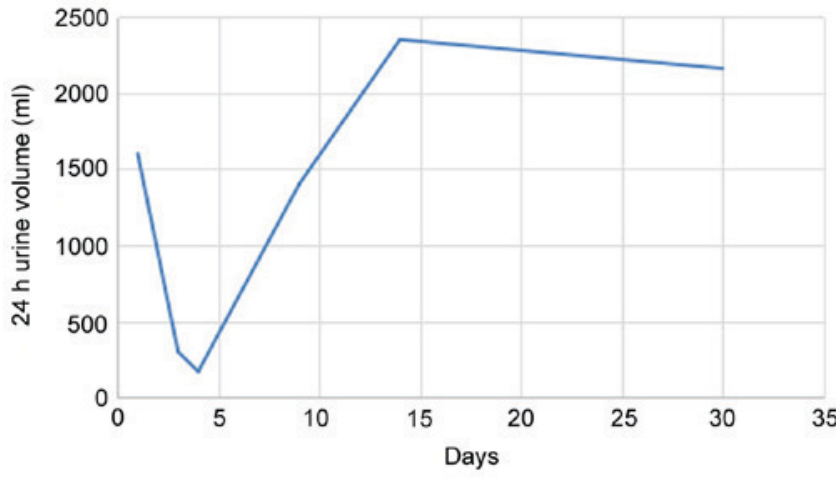

Figure 1. Patient's 24 h urine volume over time. Pantoprazole treatment ended, and RRT and prednisolone treatment started on day 1. RRT treatment ended on day 8 . RRT, renal replacement therapy.

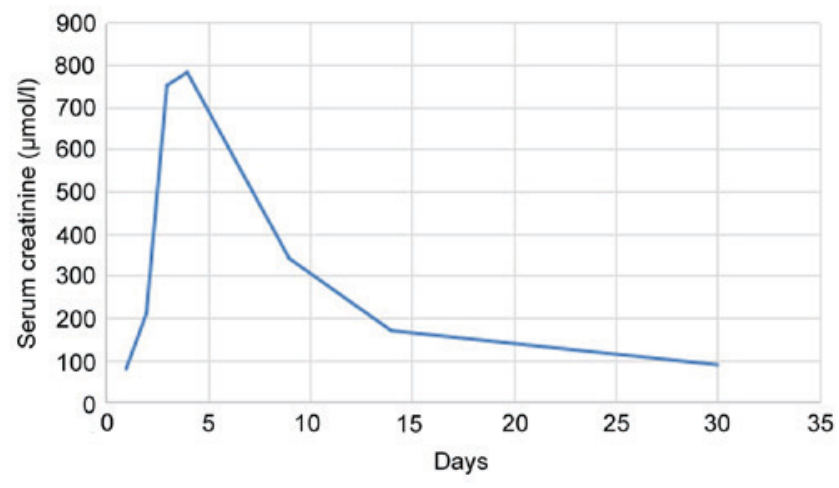

Figure 2. Patient's serum creatinine levels over time. Pantoprazole treatment ended, and RRT and prednisolone treatment started on day 1. RRT treatment ended on day 8 . RRT, renal replacement therapy.

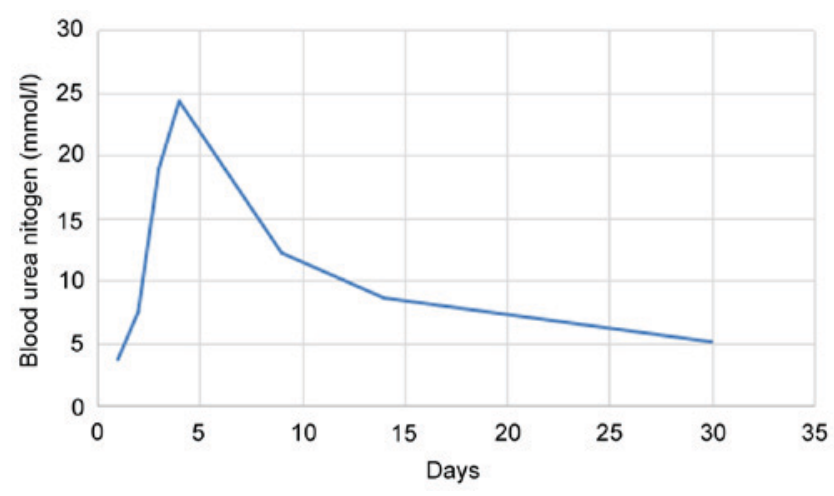

Figure 3. Patient's blood urea nitrogen levels over time. Pantoprazole treatment ended, and RRT and prednisolone treatment started on day 1. RRT treatment ended on day 8. RRT, renal replacement therapy.

respectively. The sections were then double stained with $3 \%$ uranyl acetate and lead citrate at $25^{\circ} \mathrm{C}$ for $2 \mathrm{~min}$, and embedded by epon 812 , an epoxy resin, for $30 \mathrm{~min}$ at room temperature. Electron microscopy revealed no significant proliferation or expansion of mesangial cells or matrix (Fig. 7). The capillary wall basement membrane exhibited no thickening, shrinkage or significant electron-dense deposits. The morphology of podocytes was normal and small segmental foot processes appeared fused. Tubular epithelial cells and organelles were swollen. The tubular basement membrane appeared almost 


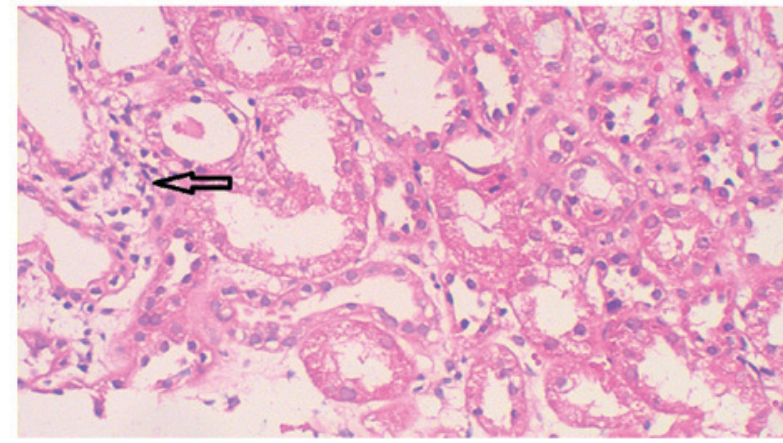

Figure 4. Hematoxylin and eosin staining of the renal cortex. The black arrow indicates interstitial edema and inflammatory cell infiltration. Magnification, $\mathrm{x} 400$.

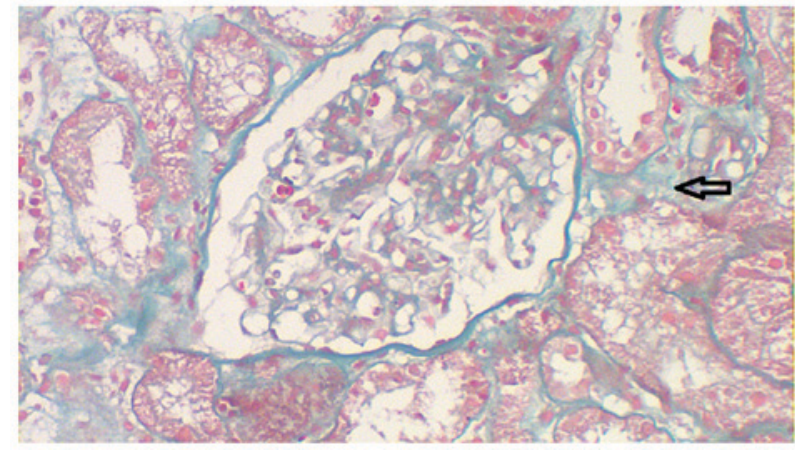

Figure 5. Masson staining of the renal cortex. The black arrow indicates interstitial edema and inflammatory cell infiltration. Magnification, x400.

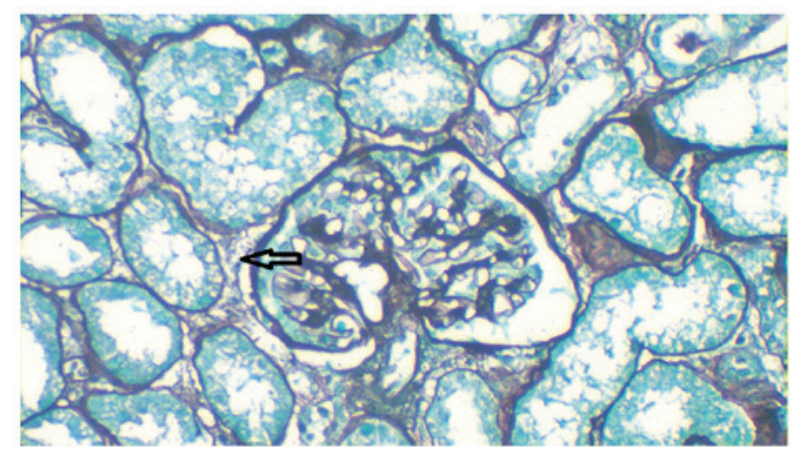

Figure 6. Periodic acid-silver methenamine staining. The black arrow indicates interstitial edema and inflammatory cell infiltration. Magnification, $\mathrm{x} 400$.

normal. Interstitial focal edema and inflammatory cell infiltration were observed. The interstitium exhibited severe edema with inflammatory cell infiltration (Fig. 7).

Based on her history, clinical manifestations and laboratory results, the patient was diagnosed with pantoprazole-induced acute kidney injury. Pantoprazole treatment was ceased and the patient was given renal replacement therapy (RRT; hemodialysis). The patient was managed with standard prednisolone ( $1 \mathrm{mg} / \mathrm{kg} /$ day) (11) and, following 5 days of treatment, $24 \mathrm{~h}$ urine volume increased to $1,400 \mathrm{ml}$, Scr decreased to $340 \mu \mathrm{mol} / \mathrm{l}$ and blood urea nitrogen was $12.2 \mathrm{mmol} / \mathrm{l}$. RRT treatment was ceased and within 2 weeks the patient's $24 \mathrm{~h}$ urine volume increased to 2,350 ml, Scr was $169 \mu \mathrm{mol} / \mathrm{l}$, Hgb was $131 \mathrm{~g} / \mathrm{l}$,

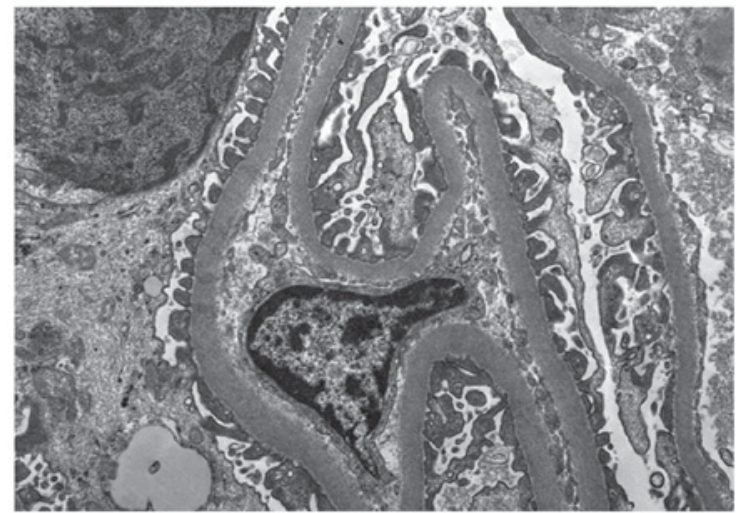

Figure 7. Electron micrograph of the renal cortex. Magnification, x15,000.

BNP was $377 \mathrm{pg} / \mathrm{ml}$, blood urea nitrogen was $8.6 \mathrm{mmol} / \mathrm{l}$ and Glu was $5.3 \mathrm{mmol} / \mathrm{l}$. The patient was discharged and follow up was performed 1 month later. At follow up, the patient's $24 \mathrm{~h}$ urine volume had increased to $2,160 \mathrm{ml}$, Scr was $88 \mu \mathrm{mol} / 1$, ESR was $11 \mathrm{~mm} / \mathrm{l}, \mathrm{Hgb}$ was $137 \mathrm{~g} / \mathrm{l}$, BNP was $169 \mathrm{pg} / \mathrm{ml}$, blood urea nitrogen was $5.1 \mathrm{mmol} / \mathrm{l}$ and Glu was $5.4 \mathrm{mmol} / \mathrm{l}$ (Figs. 1-3). Standard prednisolone was reduced according to her clinical manifestations and laboratory tests. At first $1 \mathrm{mg} / \mathrm{kg} /$ day prednisolone was administered, 2 weeks later it was reduced to $0.5 \mathrm{mg} / \mathrm{kg} / \mathrm{day}$, then $0.2 \mathrm{mg} / \mathrm{kg} / \mathrm{day} 1 \mathrm{month}$ later; after 2 months, prednisolone administration was stopped.

\section{Discussion}

Pantoprazole is used clinically to reduce gastric acid secretion (11). It is an anti-ulcer PPI derived from benzimidazole (12). Pantoprazole is able to relieve pain in patients with duodenal ulcers and improve nausea, bloating, acid reflux, belching and other ulcer-associated symptoms (13). Pantoprazole begins to act within 15-30 min of intravenous administration and $86 \%$ of gastric acid secretion is inhibited within $60 \mathrm{~min}$ (14).

The bioavailability of pantoprazole is $>75 \%$ and it is metabolized primarily in the liver without interaction with cytochrome P450 (15). As such, pantoprazole metabolism does not affect the metabolism of other drugs in the liver (16). Approximately $80 \%$ of pantoprazole metabolites are excreted by the kidneys and retained in the stool (17). The plasma clearance rate is $11 \mathrm{l} / \mathrm{h}$, as so pantoprazole has relatively fewer adverse side effects compared with other pharmacological agents (18). Side effects include occasional dizziness, insomnia, drowsiness, nausea, diarrhea, constipation, rash, muscle pain, arrhythmia, increased aminotransferases and decreased granulocytes (19).

There have been few reports of pantoprazole-induced acute kidney disease $(20,21)$. Pantoprazole-induced acute kidney injury was first reported in 2004 and there have been no more than 100 publicly reported cases (22). The patient presented here was the first case of pantoprazole-induced acute kidney disease at the Department of Nephrology, Shandong University Qilu Hospital. The mean duration of exposure to pantoprazole prior to the onset of acute kidney injury is 3 months, although it has also been reported to occur within hours of pantoprazole administration (23). The symptoms of acute kidney injury are generally nonspecific, for instance fatigue and malaise (24). Acute renal failure is the only consistent clinical presentation, although 
oliguria is unusual (24). Nausea and vomiting are present in $1 / 3$ of cases (25). In the present study, the patient was managed with pantoprazole for 2 days and reported increased nausea without vomiting, fatigue or malaise. The classic triad of fever, rash and eosinophilia was not present. Reports about proteinuria in pantoprazole-induced renal injury are rare (26) and no protein was identified in urine of the patient in the present study.

In the present case report, Scr and blood urea nitrogen were markedly increased and $24 \mathrm{~h}$ urine output was decreased compared with normal ranges following pantoprazole treatment. Following 5 days of treatment with RRT and prednisolone, these parameters were improved and continued to improve with prednisolone treatment alone until the patient was discharged 2 weeks later. Upon admission to the Department of Nephrology, a biopsy revealed that the renal pathology was consistent with acute kidney injury. Therefore, the diagnosis of pantoprazole-induced acute kidney injury was established.

Renal biopsy remains the gold standard for diagnosis. Typical histopathological findings include interstitial edema with mononuclear cells, T lymphocytes, eosinophils and plasma cell infiltration around the renal tubules, sparing the glomeruli and blood vessels $(14,26)$. Initially, interstitial fibrosis is mild and diffuse, however this may progress to tubular atrophy or extensive interstitial fibrosis and glomerulosclerosis (13). In the present study, a renal biopsy was performed two days after admission to the hospital, revealing that the patient exhibited severe edema with multifocal lymphocytes and monocytes and eosinophil infiltration. No thickening of the arterial wall in the renal interstitium was observed in light or electron micrographs.

The underlying mechanism of pantoprazole-induced acute kidney injury is complex. Sensitivity to pantoprazole is the primary reason for the onset of acute kidney injury and may only be confirmed by renal pathology (27). The standard diagnostic method for pantoprazole-induced acute kidney injury is monitoring the response to prednisone treatment (26). The use of steroids for the treatment of acute kidney injury is controversial. Intravenous Methylprednisolone pulses (250-500 mg/day for 3-4 days) followed by a tapering course of prednisone $(0.5-1 \mathrm{mg} / \mathrm{kg} /$ day) over $4-6$ weeks have been suggested as a treatment regimen for pantoprazole-induced acute kidney injury (26). In the present study, the patient was treated by discontinuing pantoprazole, administering short term RRT and long-term prednisolone management.

In the present study, the onset of acute kidney injury was clearly associated with pantoprazole administration and. Prednisolone therapy is considered to be an effective treatment for drug-induced acute kidney injury. Although the incidence of pantoprazole-induced acute kidney injury is low, the prognosis is good as long as the condition is correctly diagnosed at the earliest opportunity.

\section{Acknowledgements}

Not applicable.

\section{Funding}

The present study was supported by the Outstanding Young Scientist Research Award Fund Project of Shandong Province (grant no. BS2013YY042) and the Science and
Technology Development Plan of Shandong Province (grant no. 2014GSF121005).

\section{Availability of data and materials}

The datasets analyzed during the current study are available from the corresponding author on reasonable request.

\section{Authors' contributions}

TP, XY and ZH designed the study and drafted the manuscript. HZ and CM collected the clinical and imaging data. JZ collected and analyzed the pathological data. All authors read and approved the final manuscript.

\section{Ethics approval and consent to participate}

The study protocol was approved by the Ethics Committee of Shandong University Qilu Hospital (Jinan, China). Written informed consent was obtained from the patient after the patient and the patient's family seriously and carefully read and understood a written summary of the study plan.

\section{Consent to participate and for publication}

The patient gave her consent for the publication of this case report and accompanying images.

\section{Competing interests}

The authors declare that they have no competing interests.

\section{References}

1. Bellomo R, Kellum JA and Ronco C: Acute kidney injury. Lancet 380: 756-766, 2012.

2. Petejova $\mathrm{N}$ and Martinek A: Acute kidney injury due to rhabdomyolysis and renal replacement therapy: A critical review. Crit Care 18: 224, 2014.

3. Gaffney AM and Sladen RN: Acute kidney injury in cardiac surgery. Curr Opin Anaesthesiol 28: 50-59, 2015.

4. Peng T, Hu Z, Yang X, Gao Y and Ma C: Nitrite-induced acute kidney injury with secondary hyperparathyroidism: Case report and literature review. Medicine (Baltimore) 97: e9889, 2018.

5. Welsh C, Kasirer MY, Pan J, Shifrin Y and Belik J: Pantoprazole decreases gastroesophageal muscle tone in newborn rats via rho-kinase inhibition. Am J Physiol Gastrointest Liver Physiol 307: G390-G396, 2014.

6. Knoth H: Electrochemical behaviour of pantoprazole. Pharmazie 59: 231, 2004 (In German).

7. Schiller D, Maieron A, Schöfl R and Donnerer J : Drug fever due to a single dose of pantoprazole. Pharmacology 94: 78-79, 2014.

8. Arbel Y, Birati EY, Finkelstein A, Halkin A, Kletzel H, Abramowitz Y, Berliner S, Deutsch V, Herz I, Keren G and Banai S: Platelet inhibitory effect of clopidogrel in patients treated with omeprazole, pantoprazole, and famotidine: A prospective, randomized, crossover study. Clin Cardiol 36: 342-346, 2013.

9. Das S, Ganguly A, Ghosh A, Mondal S, Dey JK and Saha I: Oral pantoprazole-induced acute pancreatitis in an 11-year-old child. Ther Drug Monit 34: 242-244, 2012.

10. Valiente Engelhorn AL, Engelhorn CA, Salles-Cunha SX, Ehlert R, Akiyoshi FK and Assad KW: Ultrasound tissue characterization of the normal kidney. Ultrasound Q 28: 275-280, 2012.

11. Colmenares EW and Pappas AL: Proton pump inhibitors: Risk for myopathy? Ann Pharmacother 51: 66-71, 2017.

12. Lo EA, Wilby KJ and Ensom MH: Use of proton pump inhibitors in the management of gastroesophageal varices: A systematic review. Ann Pharmacother 49: 207-219, 2015. 
13. Klassen S, Krepinsky JC and Prebtani AP: Pantoprazole-induced acute interstitial nephritis. CMAJ 185: 56-59, 2013.

14. Torlot FJ and Whitehead DJ: Acute interstitial nephritis caused by two different proton pump inhibitors. Br J Hosp Med (Lond) 77: 50-51, 2016.

15. Shakhnovich V,Smith PB, Guptill JT, James LP, Collier DN, Wu H, Livingston CE, Zhao J and Kearns GL; Best Pharmaceuticals for Children Act-Pediatric Trials Network: Obese children require lower doses of pantoprazole than nonobese peers to achieve equal systemic drug exposures. J Pediatr 193: 102-108.e1, 2018.

16. Sherwood MW, Melloni C, Jones WS, Washam JB, Hasselblad V and Dolor RJ: Individual proton pump inhibitors and outcomes in patients with coronary artery disease on dual antiplatelet therapy: A systematic review. J Am Heart Assoc 4: e002245, 2015.

17. Moreira Dias L: Pantoprazole: A proton pump inhibitor. Clin Drug Investig 29 (Suppl 2): S3-S12, 2009

18. Jiao HW, Sun LN, Li YQ, Yu L, Zhang HW, Wang MF, Yu LY Yuan ZQ, Xie LJ, Chen J, et al: Safety, pharmacokinetics, and pharmacodynamics of S-(-)-pantoprazole sodium injections after single and multiple intravenous doses in healthy Chinese subjects. Eur J Clin Pharmacol 74: 257-265, 2018.

19. Aslan M, Celik Y, Karadas S, Olmez S and Cifci A: Liver hepatotoxicity associated with pantoprazole: A rare case report. Wien Klin Wochenschr 126: 390-392, 2014.

20. Kim MJ, Heim M and Mayr M: Effect of corticosteroids during ongoing drug exposure in pantoprazole-induced interstitial nephritis. Nephrol Dial Transplant. 25: 1716-1719, 2010.

21. Shao Y,Fan Y, Xie Y, Yin L, Zhang Y, Deng L, Sun X, Shao X, Tan X, $\mathrm{He} \mathrm{J}$ and Zhao S: Effect of continuous renal replacement therapy on kidney injury molecule-1 and neutrophil gelatinase-associated lipocalin in patients with septic acute kidney injury. Exp Ther Med 13: 3594-3602, 2017.
22. Moore I, Sayer JA, Nayar A, Ahmed S and Tapson JS: Pantoprazole-induced acute interstitial nephritis. J Nephrol 17 580-581, 2004

23. Simpson IJ, Marshall MR, Pilmore H, Manley P, Williams L, Thein H and Voss D: Proton pump inhibitors and acute interstitial nephritis: Report and analysis of 15 cases. Nephrology (Carlton) 11: 381-385, 2006.

24. Avinash A, Patil N, Kunder SK, Balaji O, Tilak A, Sori RK and Rao R: A retrospective study to assess the effect of proton pump inhibitors on renal profile in a south indian hospital. J Clin Diagn Res 11: FC09-FC12, 2017.

25. Ra A and Tobe SW: Acute interstitial nephritis due to pantoprazole. Ann Pharmacother 38: 41-45, 2004.

26. Sampathkumar K, Ramalingam R, Prabakar A and Abraham A: Acute interstitial nephritis due to proton pump inhibitors. Indian J Nephrol 23: 304-307, 2013

27. Geevasinga N, Coleman PL, Webster AC and Roger SD: Proton pump inhibitors and acute interstitial nephritis. Clin Gastroenterol Hepatol 4: 597-604, 2006.

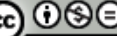

This work is licensed under a Creative Commons Attribution-NonCommercial-NoDerivatives 4.0 International (CC BY-NC-ND 4.0) License. 